University of Wollongong

Research Online

Faculty of Business - Papers (Archive)

Faculty of Business and Law

2014

The legacy of war for community-based tourism development: learnings

from Cambodia

Sotear Ellis

Lynnaire M. Sheridan

University of Wollongong, lynnaire.sheridan@otago.ac.nz

Follow this and additional works at: https://ro.uow.edu.au/buspapers

Part of the Business Commons

Research Online is the open access institutional repository for the University of Wollongong. For further information contact the UOW Library: research-pubs@uow.edu.au 


\title{
The legacy of war for community-based tourism development: learnings from Cambodia
}

\begin{abstract}
This paper investigates how resident perceptions affect the successful implementation of communitybased tourism (CBT) in a least developed country (LDC) scenario. By realizing how past and present experiences of war affect resident perceptions, including how they view themselves, their community and tourism, we can build an understanding of how to assess the capacity for a community to successfully embrace and sustain CBT for development. This will be achieved by exploring two cases of CBT in Cambodia: the Banteay Chmmar subdistrict and Banlung town. These two cases represent a successful and unsuccessful implementation of CBT in Cambodia as an LDC utilizing tourism for development. Learnings from this situation can be applied to other post-war tourism and development destinations.
\end{abstract}

\section{Keywords}

war, community, tourism, legacy, development, learnings, cambodia

Disciplines

Business

\section{Publication Details}

Ellis, S. \& Sheridan, L. M. (2014). The legacy of war for community-based tourism development: learnings from Cambodia. Community Development Journal, 49 (1), 129-142. 
Lynnaire M. Sheridan

Faculty of Commerce

University of Wollongong

Wollongong 2500

Australia.

Sotear Ellis (corresponding author)

Perth 6025

Australia

sotearellis@hotmail.com 


\begin{abstract}
This paper investigates how resident perceptions affect the successful implementation of Community Based Tourism in a Least Developed Country scenario. Central to this is how past and present experiences of war affect resident perceptions, and how this is manifested in residents' views of themselves, the community and tourism. From this, we can build an understanding of how to assess the capacity for a community to successfully embrace and sustain CBT for development. This will be achieved by exploring two cases in of CBT in Cambodia: the Banteay Chmmar subdistrict and Banlung town. These two cases represent a successful and unsuccessful implementation of CBT in Cambodia as an LDC utilising tourism for development. Learnings from this situation can be applied to other post-war tourism and development destinations.
\end{abstract}


Introduction to community based tourism development and post-war destinations

Community Based Tourism (CBT) incorporates the objectives of sustainable tourism with an emphasis on community engagement and development. The role of community development in this approach makes it appropriate for use in the LDC scenario, as tourism, with its reduced barriers to entry and ability to rely on existing and created tourism assets, is already widely accepted as a practical tool for economic stimulus (Mvula, 2001; Nettekoven, 1979; Weaver \& Lawton, 2010). CBT supports development, and promotes community control of tourism. Key to CBT, but sometimes overlooked in the desire to achieve poverty alleviation and other development aims is that CBT requires communities that are willing and able to implement and sustain tourism. Post-war destinations are often selected as 'ideal' CBT projects but, in reality, the legacy of war may not always be conducive to success as will be explored in this paper.

In summary, prolonged experiences of conflict have an impact on psychological health. Most relevant to the challenges faced by implementers of $C B T$ in this context is the damage done with respect to the ability of people to engage in long term planning and to consider community wide impacts. The experiences of people in conflict will lead to habitual short term thinking and decline in their ability to plan long term, as this will be overridden by their need to survive during conflict. This leads to a habitual pursuit of survival based activities, and a persistent selfish perspective (DicksonGomez, 2003; Marshall, Schell, Elliott, Berthold, \& Chun, 2005; Ogwo, 2010).

The implementation of CBT is likely to be challenged by residents who have experienced prolonged conflict who do not recognise the need for community wide development, and favour activities which provide immediate personal benefit. This discourages support for CBT as the long term planning and benefits which underpin this approach do not correspond to the immediate and personal needs of residents. Without significant intervention to address these symptoms attributed to Post Traumatic Stress Disorder (PTSD) (Eguren, 2008), residents in this context will not recognise or support CBT goals, and are less likely to participate in implementation. Without this initial participation, the success of $\mathrm{CBT}$ is unlikely, and the resources to be contributed by external stakeholders will be considerably more significant (Lever, Pinol, \& Uralde, 2005).

Though this discussion of post-war communities is discouraging in relation to the potential for success of CBT in many LDC scenarios, there are some situational factors which minimise these effects. Strong and cohesive community bonds are demonstrated to provide a support network for residents that reduce the prolonged effects of PTSD. Religious structures and some community behaviours related to communal work ethics and voluntarism will encourage collaboration which will override passive and aggressive responses to poverty (Harris, 2009; Kent, 2008; Prayukvong, 2005). This discussion on CBT in Cambodia will provide some insights for achieving success in post-war CBT tourism destinations. These results emerged during a larger research project, and the broader results will be submitted for publication shortly.

\section{Research Setting}

Cambodia was declared an LDC in 2001 (United Nations, 2002; United Nations Conference on Trade and Development, 2002). Currently, tourism is a priority for stimulating development (Prats, 2001). 
The focus is currently being placed on ecotourism, but Cambodia's ancient cultural history represented in the temples of Angkor and other sites remains the predominant tourism pull factor (Statistics and Tourism Information Department, 2008). There has been growth in the establishment of CBT projects in the country, though few are officially recognised by the government, and legislation still does not identify CBT. The CBT projects in Cambodia are all the result of efforts made by local and international NGOs hoping to provide communities with a sustainable means of supporting tourism in the community and stimulating community development (Cambodian Community Based Ecotourism Network, 2008).

Historically, Cambodia has experienced a lot of conflict. In the Angkorian era, prolonged fighting with the Thai and the Vietnamese contributed to the decline of the Angkorian empire and the creation of what is now modern Cambodia. There was little respite from conflict until French colonisation in 1863. Cambodia regained independence in 1953. Following this, was a time a time of prosperity before the Vietnam War crossed the Cambodian border in the sixties. It was at this time that the Khmer Rouge started to grow, before Lon Nol's coup in 1970 brought them to power. In 1975, the Pol Pot regime began, which resulted in conservative estimates of over two million deaths through genocide or starvation. The civil war continued until 1993, but residual conflict was observed in the border strongholds of the Khmer Rouge until 1996 (National Institute of Statistics of Cambodia, 2008; Ray, 2010).

The legacy of this conflict is visible in the stagnation of development and the struggle for recovery. In 2001, Cambodia turned to tourism. The increasing popularity of Cambodia as a destination has in turn encouraged international investment. The key industries in Cambodia are manufacturing (especially textiles), tourism and agriculture. Despite this trend towards growth and recovery, more than 70 per cent of the population live rurally, experiencing extreme poverty. Subsistence agriculture is still the primary occupation of the majority of the population (National Institute of Statistics of Cambodia, 2008, n.d.-a, n.d.-b). The lack of availability of modern cultivation tools and methods means that farms are small, and farmers do not produce high yield crops. Many people do not own land, and lease farm land from others and establish houses on squatted land. As such, outside the capital city of Phnom Penh, and the tourism gateway city of Siem Reap, Cambodia is in every way still an LDC.

The two locations which constitute the setting of this study are typical isolated rural communities. Banteay Chhmar is located in Banteay Meanchey province, in Cambodia's North west, approximately 40 kilometres from the Thailand border. The main village is centred around the ancient temple of Banteay Chhmar. The Banteay Chhmar temple is mostly in ruins, but includes many smaller satellite temples in the larger complex, which make up parts of the village. CBT was introduced in 2007 by the French NGO Agir Pour Le Cambodge (APLC). However, APLC was forced to withdraw prior to completion of the implementation in 2009 as a result of the global financial crisis. Today, tourism is controlled by the community with some funding provided by the NGO Global Heritage Fund (GHF), who is engaged in conserving the temple site as their own ongoing project. Tourism in Banteay Chhmar is based on visits to the temples, traditional activities, traditional foods and local homestays.

Banlung is the provincial capital of Ratanakiri, Cambodia's most isolated and inaccessible province. It is located in the North east of Cambodia. Ratanakiri is the province is home to the most diverse range of ethnic minority communities as well as the Khmer people. Many of the ethnic minority 
communities live outside the town of Banlung, in the mountainous and forested regions. Ratanakiri has the most significant amount of forest in Cambodia. Banlung relies on natural assets for tourism in the form of a volcanic lake, waterfalls and forests. These attractions are located within 15 kilometres of the townsite, with Banlung being central to these. CBT was initiated in Banlung by the national government, but the isolation of the community has limited the role of the government significantly. Tourism in Banlung is a private industry, with small community committees controlling individual attractions. There is some tourism infrastructure in Banlung, such as guesthouses and restaurants, and main activities are visiting the attractions and observing the unique cultural attractions of the ethnic groups.

\section{Method}

The research methodology was qualitative, using a basic hermeneutics approach to grounded theory, incorporating phenomenology. The primary tool for data collection was semi structured interviews. Fieldwork was conducted in two parts. Firstly, data was collected on the state of tourism in Cambodia, prior to travel to the first case study site of Banteay Chhmar. Preliminary analysis of phase one data was used to inform phase two, where data was collected in Banlung. Then a follow up in Banteay Chhmar addressed identified gaps which had arisen during preliminary analysis and outcomes from the Banlung stage of data collection. A total of 65 participants were interviewed. Following the completion of data collection, iterative and thematic analysis identified perceptions of tourism, self and community as key themes. These themes underpin the findings of this research and inform the recommendations made for optimising the implementation of CBT in the LDC scenario.

\section{Findings}

\section{Banteay Chhmar}

The key tourism of the community for attracting tourists is the main temple complex of Banteay Chhmar. The presence of the other minor temples and the living culture of the community are secondary attractions which are not perceived to draw tourists, but to add value to the primary attraction. CBT was not used as a pull factor for international tourists.

Tourism was perceived to include only the activities undertaken by the tourism committee, which included homestay accommodation, activities offered to tourists and food supplied through the tourism committee. This perception of tourism did not include any support services associated with having tourists in the community, such as tourists visiting the markets or buying goods and services elsewhere in the community. Tourists were identified as being international visitors, travelling independently or through organised tours, which used the tourism committee's services. This perception allows tourism income to be intentionally controlled by the committee, which allows for clear communication on the tangible benefits of tourism and defines the role of tourism in the community for residents.

Tourism in the community was perceived to be very positive overall by residents. It was clearly seen to have provided community wide economic benefits as well as economic benefits for direct participants. Other benefits were identified, which were community wide benefits in relation to informal education pathways, cultural and environmental conservation and improved social and economic opportunities for participants and non-participants. 'Now I have all this [homestay], I feel 
that I am very lucky, and I am happy. I have the ability to send my children to school, and I have food for my children to eat...I am very pleased with the committee.'(IBCJM09, Farmer, Banteay Chhmar)

Negative perceptions of tourism were minor, and more closely linked to potential negative impacts that would emerge as tourist numbers increased as predicted in future years. This included the risk of increased environmental pressure on the existing roads and the temples. Other potential negative impacts of tourism were linked to the external perception of the community, such as tourists seeing Banteay Chhmar as a sex tourism or drug tourism destination. Though none of these impacts were visible in the community at the time, and effort was being put into addressing them, the perceived significance of these impacts was tangible: 'Sometimes visitors appear to be okay, but in the house, they may smoke drugs... We shouldn't let it happen... If we let it happen, it could close down our program.' (IBCVPM05, Vice President, CBT Banteay Chhmar)

In Banteay Chhmar, there was an overall negative perception of self. Residents believed themselves to be generally powerless to affect change in their own lives or in the community. This powerless was linked to their experiences of conflict and poverty, as described by residents: 'I think the problems are because our country was at war. ...we have been affected by too many wars.' (Homestay owner and farmer, Banteay Chhmar)

Residents participating in tourism downplayed their individual role in their contribution to tourism as a benefit of the community, despite the emphasis they placed on the positive impacts of tourism. Individual residents were not willing to create opportunities for the community, and only engaged in limited individual entrepreneurship. The idea of tourism was strongly attributed to the original NGO who initiated CBT in Banteay Chhmar, despite their premature withdrawal and the success of the community in operating and further developing $C B T$ independently.

This perception of self was in contrast to individual resident's perception of community. Collectively, the community was perceived to be strong and capable of affecting change. The community was credited with achieving the development goals from tourism, and was judged to be fair and transparent. As a whole, the community was capable of seeking and pursuing opportunities to develop tourism, which would be translated into opportunities for the whole community, and an extension of benefits. The community was also perceived to be capable of working to prevent negative impacts of tourism, such as being strong enough to resist the entry of sex tourism and drug tourism.

This positive view of community has led to the positive perception and high functionality of the tourism committee. Being made up of a range of community members (which includes a balance of community representatives in respect to income, assets and occupation) and representative of tourism as a whole, the tourism committee is empowered by the positive perception of tourism and the community. This allows the tourism committee to have responsibility for tourism and the impacts it has on the community. Being a representative of 'community' rather than perceived as a group of individuals, the tourism committee is active in identifying and responding to opportunities and advocating for the community on a range of issues beyond tourism. Their current performance in this role has gained the trust and support of the community, which further strengthens positive perceptions tied to the idea of 'community' over the individual. 
'The most important thing is our goals, so that our local area develops and progresses further. Before we can become developed, you have to make sacrifices, like time, to participate for the benefit of the community.' (Homestay owner, Banteay Chhmar)

\section{Banlung}

Banlung differs from Banteay Chhmar in that the key assets for tourism are perceived to be key attractions, rather than pull factors for the destination itself. The tourism assets are defined as the waterfall sites, the volcanic lake, and generally, the natural environment. The secondary factor is the unique living culture of the ethnic minority communities, which includes different culture, arts and crafts. These attractions are considered and controlled in isolation.

Tourism in Banlung is perceived to include tourists visiting these primary sites, as well as the use of support services. This includes shopping, staying in privately owned accommodation, visiting the markets, and eating in the restaurants. Though international tourists are considered to be of the most importance, the community does recognise leisure and domestic tourism.

Overall, tourism is considered to be positive for the community by the community. It provides mostly economic benefits, which include increased employment and entrepreneurial opportunities for individuals. Tourism is also credited with being a force for environmental and cultural conservation, which is particularly valued due to the uniqueness of both environmental and cultural aspects. Few negative impacts of tourism were identified. The negative impacts of tourism were related to poor behaviour of domestic tourists, and not international tourists. International tourists were considered to behave more appropriately ad in the best interests of the community. The risks of negative impacts which had been identified by the community was a key point of concern for residents. The fear of exploitation by tourists, and the emergence of sex and drug tourism was common to the potential impacts perceived in Banteay Chhmar. However, these perceived risks were already having a tangible effect on resident perceptions, as ethnic minority residents were leaving the area for fear of increasing sex and drug tourism. This was the result of awareness campaigns being conducted by NGOs on potential negative impacts of tourism, and not necessarily as a result of impacts perceived by the residents themselves.

The perception of self in Banlung was, like Banteay Chhmar, negative overall. Residents felt disempowered to affect change in their lives or their community 'If I was going to do it myself, I don't think I could, because I do not have the capabilities to make it work...If I could, I would like to be elected as a president[CBT]' (Resident, Banlung) Interestingly, though perceptions of self were negative, residents displayed more entrepreneurship and identified the potential opportunities they had for affecting change. This negative perception of their own abilities was affected by their perception of community. They could identify opportunities for change, but were unwilling to challenge the status quo in the community, or disregarded their ideas for being too hard.

The perception of community in Banlung was very different to perceptions in Banteay Chhmar. The larger size of the community and the cultural diversity within led to isolation of some sectors and the establishment of internal community groups based on cultural ethnicity. This is compounded by the different languages being used in the community, which hinders effective communication between cultural groups. Each attraction was perceived to be the responsibility of an individual group, with no larger control. Because of the divided nature of tourism and the community, the community was not 
perceived to be a cohesive unit. Therefore, the community was perceived to be powerless and ineffective at advocating for the community, as individual groups had their own priorities and goals: 'I would like this community to wake up... To not think of themselves all the time ... They think that CBT doesn't benefit them, so every day, they go to collect cashew nuts instead, planting the fields, doing other things for themselves more than the community.' (Resident, Katieng Waterfall, Banlung).

This could be considered the reason for the lack of an effective tourism committee in Banlung. The powerlessness of the community puts the responsibility on the individual, where residents were disinclined to contribute to community goals by participating in CBT via the tourism committee. Also, the internal community groups and conflict based on poor communication and varied cultural viewpoints do not support the creation of an effective tourism committee that can balance the responsibility for bridging the gaps between these groups and work for collective development goals via tourism. As such, the tourism committee in Banlung is dysfunctional, as key members lack the commitment to pursuing CBT goals in preference of their individual goals, and without this direction, have for the most part, ben relegated to a reactive policing role for tourism in the community. Their achievements are in relation to the prevention of major negative impacts from tourism by highlighting emergent issues.

\section{Discussion}

Tourism in both communities was seen to be positive overall. It is important to note, however, that the dependence of residents on immediate economic benefits is likely to skew this perception positively in the LDC scenario (Blau, 1969). However, negative impacts of tourism were identified by residents in each community. The majority of these were seen to be potential impacts, where residents identified the threat of these impacts emerging in the future as important. The role of fear in the premature identification of negative impacts will affect overall perceptions of tourism, and represents serious points of consideration for communities be addressed during tourism development (Ellis and Sheridan, 2009). This vulnerability is directly linked to poverty and war, and the lack of resources and uncertainty experienced in both cases. This is clearly demonstrated by residents in Banlung opting to relocate to avoid potential negative impacts of tourism described to them through educational campaigns conducted by NGOs. This phenomenon cannot be identified through traditional impact assessment approaches, suggesting that this must be taken into consideration and built into existing techniques.

The way tourism is perceived in the community influences how residents perceive CBT. In Banteay Chhmar, tourism is perceived to include only the activities managed by the tourism committee, and the aims of tourism as a support for community development goals. This perception contributes to positive perceptions of tourism and CBT by controlling expectations for tourism and linking community development goals and community wide benefit to only CBT activities. This is contrasted by the perception in Banlung, where tourism is viewed as an industry made up of private businesses, and CBT is largely overlooked. Therefore, tourism is perceived to have few community wide benefits. This reinforces the importance of personal benefits, fails to moderate expectations of tourism and does not establish a link between tourism and community development. This in turn limits the success of $C B T$ as residents do not perceive that $C B T$ supports development goals. When tourism is defined by CBT related activities, the perception of the community will naturally be supportive, 
identifying realistic expectations and linking development goals directly to tourism activities and CBT. The argument can be made that these perspectives are grounded in the communities' individual responses to poverty, being passive and dependent on external implementation and definition of tourism in Banteay Chhmar, or entrepreneurial and viewing tourism as a private industry in Banlug.

In the disempowered LDC scenario, residents consistently undervalue themselves, and depend on third parties for support (Akpabio, Eniang, \& Egwali, 2008; Lever, et al., 2005; Rogerson, 2007; Suntikul, Bauer, \& Song, 2010; Teye, Sonmez, \& Sirakaya, 2002). This is demonstrated by the poor perception of self in both cases. Experiences of conflict and chronic poverty has consequences for the success of CBT as it affects long term planning and collaborative behaviour and does not encourage support for tourism or active participation (Dickson-Gomez, 2003; Marshall, et al., 2005; Mollica et al., 1993).

The negative impacts of PTSD related to experiences of war and the effects of chronic poverty have been shown to have had negative outcomes for residents in Banteay Chhmar. Residents in this community have had a more passive response, poorer perception of self, and no perceived ability to mobilise and change their own situation. In Banlung, some entrepreneurial spirit has emerged as an active response to chronic poverty, but with diminished capacity for long term planning, this response will not have a long term benefits for the community.

It is clear that CBT in Banteay Chhmar, at this point, is more successfully achieving community development goals. This suggests that there are other factors which contribute to minimising the impact of negative perceptions of self. The key difference identified between the two cases is the perception of community. Perception of community is more positive and inclusive in Banteay Chhmar in comparison to Banlung. The community is overall quite cohesive. Residents see the community as collaborative, and empowered. The cohesiveness of the community further supports this perception and establishes a sense of trust which allow the individuals to work for the community interests, regardless of how they perceive themselves. It also promotes open communication and inclusion of all community members, regardless of their role in tourism, or the community. In Banlung, poor cohesion, ethnic diversity and lack of trust undermines the sense of community, creates communication barriers, and prevents community wide collaboration (George, 2008; Harris, 2009; Manyara \& Jones, 2007).

Where the perception of self in each case is negative, it is clear from these two cases that the perception of the community is not necessarily correlated to perception of self. Therefore, establishing a close and cohesive community is a key factor for minimising the negative impacts of poor perception of self, such as poor capacity for long term planning and dependency on third parties. A cohesive and collaborative community can provide an environment that limits the impact and facilitates self healing of PTSD by providing strong village links, supportive long term relationships, and promoting collaborative values (through religion, for example). Also, the strength of the community can empower the collective group where individuals feel disempowered (Harris, 2009; Kent, 2008; Prayukvong, 2005).

To facilitate the successful implementation of CBT in the LDC scenario, the perceptions of residents must be taken in account. It is an opportunity to highlight some of the underlying issues arising from experiences of conflict and poverty, both common in this context. This is vital for successfully 
implementing CBT. Most importantly, how residents perceive tourism impacts may not correlate with observable impacts, as the fear of potential impact is significant enough to colour perceptions negatively. This can even overcome the dependence on economic benefits which can skew overall perceptions of tourism positively.

Specific to CBT, the perceptions of self and community have meaning for successful implementation. Poor perception of self is potentially common in LDC communities utilising CBT for development. It can prevent active participation in CBT and also undermine support for tourism as a development tool. Support is essential for the benefit of the product, host guest relations and long term sustainability by increasing tolerance for tourism in the community (Carbone, 2005; Nettekoven, 1979; Suntikul, et al., 2010; Ying \& Zhou, 2007). Active participation in CBT is a core part of the CBT product, and supports development goals by ensuring community participation in decision making.

Though poor perception of self is likely to be common in disadvantaged communities (in Cambodia and LDCs with a similar historical background), perception of community has more impact on the successful implementation of CBT. Where there is a strong, open, collaborative and communicative community, it is suggested that this provides a support network for individual residents that promotes recovery from potential psychological harm arising from war and poverty(Eguren, 2008; Harris, 2009). This empowers individuals collectively as a community, and minimises the effects of poor perception of self.

Community cohesion is a powerful facilitator of successful CBT. A strong sense of community provides a safe and secure social environment that minimises the impact of PTSD following experiences of war, and collectively empowers individual residents for pursuing community goals, even in LDC communities where poverty is a common issue. This supports the implementation of $\mathrm{CBT}$, as residents will recognise the need to plan for longer term community wide benefits and balance this with their immediate needs. Communication is also facilitated by a collaborative community environment, which is a key factor for establishing realistic expectations, goals, and ensuring CBT's sustainability.

\section{Conclusion}

For the successful implementation of CBT, the capacity of the community must be assessed based on perceptions, collaboration and communication. These characteristics will determine the capacity for the community to engage a supported and functional tourism committee, and maintain support for tourism and development through ongoing education and communications.

Based on these findings, an assessment tool must be developed for implementers to evaluate the capacities of communities prior to implementing CBT to promote success. Indicators must incorporate observational and perceptions based measures to address the unique issue of fear in affecting resident perceptions of tourism impacts (Ellis \& Sheridan, 2009). This notion of fear has the potential to have more widespread consequences, in other LDC communities outside Cambodia (such as those sharing a long history of poverty and war).

All development in these contexts must consider the effects of chronic poverty and conflict on the mental wellbeing of residents. Recognising the issues that arise will facilitate the implementation of 
any project by external stakeholders and identifies the need to consider treating psychological symptoms in communities as a means of capacity building.

The notion of fear related to impacts of tourism highlights the need to review current approaches to educating vulnerable communities about tourism impacts. Though this is currently seen as important to increase residents' awareness of tourism and balance resident expectations (Mvula, 2001; Scheyvens \& Momsen, 2008), the way potential negative impacts are perceived by residents through the lens of fear is likely to adversely affect support for tourism, increasing negative impacts, not preventing them.

Further research is required to enable a community assessment tool to be developed to facilitate the efficient implementation of CBT in LDC communities, and to explore the full implications of war and chronic poverty on communities and their capacities. In Cambodia, the issue of fear necessitates an adaptation of how communities are prepared to respond to the introduction of tourism. Fear must also be explored in other LDC communities to determine the extent of the effect it has on the implementation of CBT in other contexts

\section{References}

Akpabio, I. A., Eniang, E. A., \& Egwali, E. C. (2008). Socio-economic potentials and environmental implications of coastal tourism at Adiabo, Cross River State, Nigeria. Environment, Development and Sustainability, 10(3), 249.

Blau, P. M. (1964). Exchange and Power in Social Life. New York: J. Wiley

Cambodian Community Based Ecotourism Network. (2008). CBET Projects. Retrieved 21 February, 2011, from www.ccben.org

Carbone, M. (2005). Sustainable Tourism in Developing Countries: Poverty Alleviation, Participatory Planning, and Ethical Issues. The European Journal of Development Research, 17 (3), 559565.

Dickson-Gomez, J. (2003). Growing Up in Guerrilla Camps: The long term impact of being a child soldier in El Salvador's Civil War. Ethos, 30(4), 327-356.

Eguren, I. R. (2008). Moving Up and Down the Ladder: Community-based participation in public dialogue and deliberation in Bolivia and Guatemala. Community Development Journal, 43(3), 312-328.

Ellis, S., \& Sheridan, L. (2009). Host Guest Relations in a LDC Context: An exploratory study of the social dynamic of tourism in Cambodia. Paper presented at the Council for Australian University Tourism and Hospitality Education 18th Tourism and Hospitality Education and Research Conference, Fremantle, Western Australia.

George, B. P. (2008). Local community's support for post-tsunami recovery efforts in an agrarian village and a tourist destination: a comparative analysis. Community Development Journal, 43(4), 444.

Harris, R. W. (2009). Tourism in Bario, Sarawak, Malaysia: A case study of pro-poor community based tourism integrated into community development. Asia Pacific Journal of Tourism Research, 14(2), 125-135.

Kent, A. (2008). Peace, Power and Pagodas in Present Day Cambodia. Contemporary Buddhism, 9(1), 77-97.

Lever, J. P., Pinol, N. L., \& Uralde, J. H. (2005). Poverty, Psychological Resources and Subjective Well Being. Social Indicators Research, 73, 375-408.

Manyara, G., \& Jones, E. (2007). Community-based Tourism Enterprise Development in Kenya: An exploration of their potential as avenues of poverty reduction. Journal of Sustainable Tourism, 15(6), 628-644. 
Marshall, G. N., Schell, T. L., Elliott, M. N., Berthold, S. M., \& Chun, C.-A. (2005). Mental Health of Cambodian Refugees 2 Decades After Resettlement in the United States. Journal of the American Medical Association, 294(5), 571-579.

Mollica, R. F., Donelan, K., Tor, S., Lavelle, J., Elias, C., Frankel, M., et al. (1993). The Effect of Trauma and Confinement on Functional Health and Mental Health Status of Cambodians Living in Thailand-Cambodia Border Camps. Journal of the American Medical Association, 270(5), 581586.

Mvula, C. D. (2001). Fair Trade in Tourism to Protected Areas: A micro case study of wildlife tourism to South Luangwa National Park, Zambia. The International Journal of Tourism Research, 3(5), 393.

National Institute of Statistics of Cambodia. (2008). Statistical Yearbook of Cambodia 2008 (English ed.). Phnom Penh: National Institute of Statistics of Cambodia.

National Institute of Statistics of Cambodia. (n.d.-a). Cambodia Socio-Economic Survey 2004. Retrieved 3 October, 2008, from http://statsnis.org/SURVEYS/CSES2003-04/

National Institute of Statistics of Cambodia. (n.d.-b). National Accounts of Cambodia 2003-2005. Retrieved 23 September, 2008, from http://www.stats.nis.gov.kh/PERIODIC/NA/Table1.htm

Nettekoven, L. (1979). Mechanisms of Intercultural Interaction. In E. de Kadt (Ed.), Tourism: Passport to Development (pp. 135-145). Washington D.C.: Oxford University Press.

Ogwo, A. (2010). A Review of the Effects of Armed Conflict on Children: Psychological implications. Ife PsychologIA, 18(2), 236-252.

Prats, F. (2001). Tourism and Sustainable Development in the LDCs Tourism in the Least Developed Countries (pp. 145-161). Madrid: World Tourism Organization.

Prayukvong, W. (2005). A Buddhist Economic Approach to the Development of Community Enterprises: a case study from Southern Thailand. Cambridge Journal of Economics, 29, 1171-1185.

Ray, N. (2010). Cambodia (7th ed.). London: Lonely Planet.

Rogerson, C. M. (2007). Tourism Routes as Vehicles for Local Economic Development in South Africa: The Example of the Magaliesberg Meander. Urban Forum, 18(2).

Scheyvens, R., \& Momsen, J. H. (2008). Tourism and Poverty Reduction: Issues for Small Island States. Tourism Geographies, 10(1), 22.

Statistics and Tourism Information Department. (2008). Tourism Statistics: Annual Report 2008. Phnom Penh: Ministry of Tourism.

Suntikul, W., Bauer, T., \& Song, H. (2010). Towards Tourism: a Laotian perspective. International Journal of Tourism Research, 12, 449-461.

Teye, V., Sonmez, S. F., \& Sirakaya, E. (2002). Residents' Attitudes Towards Tourism Development. Annals of Tourism Research, 29, 668-688.

United Nations. (2002). The Criteria for the Identification of LDCs. Retrieved 29 April, 2011, from http://www.un.org/special-rep/ohrlls/ldc/ldc\%20criteria.htm

United Nations Conference on Trade and Development. (2002). UN Recognition of Least Developed Countries. Retrieved 18 October, 2007, from http://www.unctad.org/Templates/Page.asp?intltemID=3618\&lang=1

Weaver, D., \& Lawton, L. (2010). Tourism Management (4th ed.). Milton: John Wiley and Sons.

Ying, T., \& Zhou, Y. (2007). Community Governments and External Capitals in China's Rural Cultural Tourism: A comparative study of two adjacent villages. Tourism Management, 28, 96-107. 